OPEN ACCESS

Edited by:

Ondřej Šeda,

Charles University, Czechia

Reviewed by:

Dietmar Fuchs,

Innsbruck Medical University, Austria

Yukihiro Fujita,

Shiga University of Medical Science,

Japan

${ }^{*}$ Correspondence:

Sung Hee Cho

shchoimd@gmail.com

Specialty section: This article was submitted to

Diabetes,

a section of the journa

Frontiers in Endocrinology

Received: 15 October 2018

Accepted: 18 January 2019

Published: 28 February 2019

Citation:

Lee J-E, Oh TJ, Moon JH, Park KS, Jang HC and Choi SH (2019) Serum

Neopterin Concentration and Impaired

Glucose Metabolism: Relationship

With $\beta$-Cell Function and Insulin

Resistance. Front. Endocrinol. 10:43.

doi: 10.3389/fendo.2019.00043

\section{Serum Neopterin Concentration and Impaired Glucose Metabolism: Relationship With $\beta$-Cell Function and Insulin Resistance}

\author{
Jie-Eun Lee ${ }^{1}$, Tae Jung Oh ${ }^{1}$, Jae Hoon Moon ${ }^{1}$, Kyong Soo Park ${ }^{2}$, Hak Chul Jang ${ }^{1}$ and \\ Sung Hee Choi ${ }^{\text {* }}$ \\ ${ }^{1}$ Department of Internal Medicine, Seoul National University Bundang Hospital, Seongnam, South Korea, ${ }^{2}$ Department of \\ Internal Medicine, Seoul National University Hospital, Seoul, South Korea
}

\begin{abstract}
Aim: The purpose of this study was to measure the serum neopterin according to glucose metabolism and to evaluate neopterin as a predictor of type 2 diabetes (T2D) in a hospital-based cohort.
\end{abstract}

Methods: A 75-g oral glucose tolerance test (OGTT) was performed by people who visited the outpatient clinic in Seoul National University Bundang Hospital for suspected abnormal glucose tolerance or a strong family history of T2D. Neopterin was measured using an enzyme-link immunosorbent assay with baseline samples from the OGTT.

Results: Neopterin was measured in 184 participants. Indices related to glucose metabolism, such as the HOMA-IR, disposition index, etc. were calculated based on the results of the OGTT. The classifications for the 184 participants were: 24 (13\%) had NGT, 89 (48.4\%) prediabetes, and 60 (38.6\%) T2D. Neopterin increased with deterioration of glucose metabolism ( $0.55 \pm 0.25$ vs. $0.58 \pm 0.27$ vs. $0.67 \pm 0.27 \mathrm{ng} / \mathrm{ml}, p=0.041$; NGT, prediabetes, and T2D, respectively). Neopterin also correlated with fasting plasma glucose, 30-min and 120-min glucose of OGTT and HbA1c ( $r=0.251,0.259,0.184$, and 0.270, all $p<0.05)$. The HOMA-IR and disposition index correlated with neopterin $(r=0.291$ and -0.170 , respectively, both $p<0.05)$. When combined with C-peptide level, neopterin was as powerful as HOMA-IR in predicting future T2D.

Conclusion: Serum neopterin appears to be related to impaired insulin secretion and insulin resistance in the development of T2D. Further investigation of the relationship between neopterin and glucose metabolism would be helpful to understand the pathophysiology for the development of T2D.

Keywords: neopterin, kynurenine pathway, insulin resistance, $\beta$-cell function, impaired glucose metabolism

\section{INTRODUCTION}

Type 2 diabetes (T2D) is an important chronic disease because of the large number of people with T2D and its severe complications, which are responsible for increased morbidity and mortality. T2D is a complex metabolic disorder, and its pathogenesis is thought to have several mechanisms (1). One commonly held view is that risk factors, such as obesity, genetic factors, aging, and 
metabolic syndrome result in lipolysis and increased levels of circulating non-essential fatty acids. These factors can cause insulin resistance and lead to hyperglycemia, which has a further effect in reducing insulin secretion via "glucose toxicity" (2).

In 1997 and 1998, a new concept for the pathogenesis of T2D was proposed, which is that chronic inflammation and the innate immune system were closely involved $(3,4)$. Since then, many studies have shown that circulating markers of inflammation and acute-phase reactants are strong predictors of the development of T2D (5-9). In addition, there were reports of the role of adaptive immunity in obesity and related disease, such as insulin resistance in recent years (10-14). One implication of the results of these studies is that there may be a relationship between inflammation and diabetes; if so, inflammatory markers may be useful for refining $\mathrm{T} 2 \mathrm{D}$ risk prediction and better targeting of individuals for lifestyle interventions.

Impaired glucose tolerance is one of the major risk factors for $\mathrm{T} 2 \mathrm{D}$, and the annualized conversion rate to $\mathrm{T} 2 \mathrm{D}$ is $5-10 \%$ (15). Understanding the mechanisms through which prediabetes develops into $\mathrm{T} 2 \mathrm{D}$ is important for the prevention and treatment of T2D. Inflammation is a prominent risk factor for the development of $\mathrm{T} 2 \mathrm{D}$ in people with prediabetes (16). Neopterin, which is produced by activated macrophages/monocytes primarily upon stimulation by interferon- $\gamma($ IFN- $\gamma)$, is a potential marker of immune activation.

At present, serum neopterin level is used primarily for diagnosing or predicting the prognosis of various diseases. The neopterin levels in body fluids are elevated by infection, autoimmune disease, malignancy, allograft rejection, cardiac and renal failure, coronary artery disease, and myocardial infarction (17). Neopterin is also known to be a byproduct of the kynurenine pathway, which is a metabolic pathway leading to the production of nicotinamide adenine dinucleotide (NAD) from the degradation of the essential amino acid tryptophan. The clinical and experimental data on the involvement of tryptophan metabolites in the pathogenesis of T2D were reviewed in 1985 (18). Pro-inflammatory factors, such as IFN- $\gamma$ or lipopolysaccharide activate the upstream steps of the kynurenine pathway (i.e., conversion of tryptophan into kynurenine and kynurenine into 3-hydroxykynurenine) through activation of tryptophan-or indoleamine-2,3dioxygenases and of kynurenine monooxygenase (19). These pro-inflammatory factors also divert downstream of the kynurenine pathway from the biosynthesis of NAD toward formation of diabetogenic downstream metabolites, such as kynurenine, xanthurenic acid, and kynurenic acid $(20,21)$. Concurrently with induction of indoleamine2,3-dioxygenases, proinflammatory factors (e.g., IFN- $\gamma$, tumor necrosis factor- $\alpha$, interleukin-1 $\beta$ ) activate guanosine triphosphate cyclohydrolase, which catalyzes conversion of guanosine triphosphate to 7,8-dihydroneopterin (22) and results in the increased formation of a stable, water-soluble neopterin (23).

Many lines of evidence have shown that activation of the immune system and chronic inflammation are involved in the pathogenesis of T2D. Neopterin may be a possible biomarker for predicting T2D. The aim of our study was to measure the serum concentration of neopterin according to glucose metabolism status and to determine whether neopterin concentration is a predictor of future T2D in a hospital-based cohort.

\section{MATERIALS AND METHODS}

\section{Study Population and Diagnosis of T2D}

A total of 184 subjects were randomly selected from a hospitalbased cohort of patients who visited the outpatient clinic of the endocrinology department at Seoul National University Bundang Hospital (SNUBH) from 2005 to 2014 because of suspected abnormal glucose tolerance or a family history of T2D. They undertook a 75-g oral glucose tolerance test (OGTT), and blood glucose level was measured at 0,30 , and $120 \mathrm{~min}$. The study participants were categorized according to the criteria for the diagnosis of T2D in the 2016 American Diabetes Association (ADA) guidelines (24). NGT was defined as a fasting plasma glucose $(\mathrm{FPG})$ concentration $<100 \mathrm{mg} / \mathrm{dl}$, 2-h post-prandial glucose $(\mathrm{PG})<140 \mathrm{mg} / \mathrm{dl}$, and glycated hemoglobin (HbAlc) $<5.7 \%$. Prediabetes was defined as FPG 100-125 mg/dl, 2-h PG 140-199 mg/dl, or HbA1c 5.7-6.4\%. T2D was defined as FPG $\geq 126 \mathrm{mg} / \mathrm{dl}, 2-\mathrm{h} \mathrm{PG} \geq 200 \mathrm{mg} / \mathrm{dl}$, or $\mathrm{HbAlc} \geq 6.5 \%$. In the T2D group, newly diagnosed, drug-naïve patients were enrolled. Information about concomitant disease, medical history, and family history were collected through a retrospective review of medical records. People with pancreatic cancer, gestational diabetes, or type 1 diabetes, or those who used an insulin or oral hypoglycemic agent were excluded from the study. It was also confirmed whether there were inflammatory diseases, such as rheumatoid arthritis or infection known to affect the concentration of neopterin. The study was approved by the Institutional Review Board (IRB) of SNUBH (IRB No. L-2016480-4) and complied with the Declaration of Helsinki (version 2008). Informed consent was waived by IRB because of the retrospective nature of the study.

\section{Laboratory Measurements}

Venous blood was sampled after an 8 -h fast. Samples were stored at $-80^{\circ} \mathrm{C}$ immediately after blood withdrawal. Plasma glucose level was measured using a Hitachi 747 chemistry analyzer (Hitachi, Tokyo, Japan). HbA1c level was determined using a Bio-Rad variant II Turbo HPLC analyzer (BioRad, Hercules, CA, USA) in the National Glycohemoglobin Standardization Program (NGSP) level II-certified laboratory at SNUBH. Plasma C-peptide and insulin concentrations were measured by radioimmunoassay (Linco, St. Charles, MO, USA). The fasting plasma concentration of total cholesterol, triglyceride, and high-density lipoprotein (HDL) and low-density lipoprotein (LDL) cholesterol were measured using a Hitachi 747 chemistry analyzer. Neopterin concentration was measured using commercially available ELISA kit (IBL International, Germany) in baseline samples from the OGTT. HbAlc, serum glucose, Cpeptide, and insulin levels were measured in fresh plasma and neopterin concentration was assessed in frozen plasma. 


\section{Indices of $\beta$-Cell Function, Insulin Sensitivity, and Insulin Resistance}

The homeostasis model assessment of insulin resistance (HOMA-IR) index was calculated as fasting insulin $(\mu \mathrm{U} / \mathrm{ml})$ $\times$ FPG $(\mathrm{mg} / \mathrm{dl}) / 405$ as described by Matthews et al. (25). HOMA- $\beta$ was calculated using the following formula: $360 \times$ fasting insulin concentration $(\mu \mathrm{U} / \mathrm{ml}) /[\mathrm{FPG}(\mathrm{mg} / \mathrm{dl})-63]$. The 30-min insulinogenic index, an indicator of early phase insulin release, was calculated as [30-min insulin concentration $(\mu \mathrm{U} / \mathrm{ml})$ - fasting insulin concentration $(\mu \mathrm{U} / \mathrm{ml})] /[30-\mathrm{min}$ glucose concentration (PP30) (mg/dl) - FPG (mg/dl)] (26). The disposition index, which reflects $\beta$-cell function, was calculated as [30-min insulin concentration $(\mu \mathrm{U} / \mathrm{ml})$ - fasting insulin concentration $(\mu \mathrm{U} / \mathrm{ml})] /[\mathrm{PP} 30(\mathrm{mg} / \mathrm{dl})-\mathrm{FPG}(\mathrm{mg} / \mathrm{dl})] / \mathrm{HOMA}-$ IR $(27,28)$. The mean glucose and insulin concentrations were calculated from values at $0,30,120 \mathrm{~min}$ of the OGTT using the trapezoidal rule (29). The ratio of fasting glucose to insulin concentrations was measured to assess insulin sensitivity (30).

\section{Statistical Analysis}

The data are expressed as mean with standard deviation (SD). All participants were categorized into three groups according to the 2016 ADA guidelines: NGT, prediabetes, and T2D. Significant differences in baseline characteristics were identified using the chi-squared test for categorical variables and Student's $t$-test or the Mann-Whitney $U$ test for continuous variables. The baseline characteristics were analyzed according to the glucose metabolism status. The concentration of serum neopterin was square root transformed to achieve normal distribution and homogeneity of residuals. The relationships between neopterin concentration and the glucose-related parameters were analyzed using Pearson's correlation. Receiver operating characteristic curve (ROC) analysis (c-statistics) was used for predicting T2D, and differences in the area under the curve (AUC) between models were tested using the non-parametric method of DeLong et al. (31). In general, $p$-values $<0.05$ were considered to indicate significant associations. Statistical data analyses were performed using IBM SPSS Statistics (version 22.0; IBM Corp., Armonk, NY, USA).

\section{RESULTS}

\section{Patient Characteristics}

A total of 184 participants aged 21-88 years were included. Twenty-four (13\%) were classified as having NGT, 89 (48.4\%) as having prediabetes, and $60(38.6 \%)$ as having T2D. Their baseline characteristics are shown in Table 1. Their mean age was $52.1 \pm 12.3$ years, and their mean BMI was $25.0 \pm 3.8$ $\mathrm{kg} / \mathrm{m}^{2}$. For all participants, the median neopterin concentration was $0.366 \mathrm{ng} / \mathrm{ml}$ (interquartile rage, 0.156-0.627). Neopterin concentration did not differ significantly according to age, sex or smoking history (data not shown), but was significantly related to BMI $(r=0.201, p<0.05)$. Neopterin concentration was also significantly higher in patients with T2D than in those with NGT or prediabetes but did not differ significantly between the NGT and prediabetes groups (Table 1). White blood cell count and Creactive protein concentration, a clinical marker of inflammation, were higher in patients with T2D than in those with NGT.
TABLE 1 | Baseline characteristics of the study participants.

\begin{tabular}{|c|c|c|c|c|}
\hline & $\begin{array}{c}\text { NGT } \\
\text { Mean } \pm \text { SD }\end{array}$ & $\begin{array}{l}\text { Prediabetes } \\
\text { Mean } \pm \text { SD }\end{array}$ & $\begin{array}{c}\text { T2D } \\
\text { Mean } \pm \text { SD }\end{array}$ & $p$ \\
\hline ge, years & $47.8 \pm 13.6$ & $56.8 \pm 9.8$ & $47.5 \pm 12.6$ & $<0.001$ \\
\hline $\mathrm{BMI}, \mathrm{kg} / \mathrm{m}^{2}$ & $23.4 \pm 2.7$ & $24.5 \pm 3.0$ & $26.2 \pm 4.6$ & 0.002 \\
\hline SBP, mmHg & $123.6 \pm 15.4$ & $125.1 \pm 14.5$ & $122.8 \pm 14.4$ & 0.646 \\
\hline $\mathrm{DBP}, \mathrm{mmHg}$ & $73.4 \pm 7.2$ & $76.3 \pm 9.9$ & $78.3 \pm 9.5$ & 0.191 \\
\hline Cholesterol, mg/dl & $196.6 \pm 24.9$ & $195.2 \pm 36.2$ & $213.0 \pm 45.5$ & 0.016 \\
\hline Triglyceride, mg/dl & $134.4 \pm 120.6$ & $153.4 \pm 150.2$ & $202.2 \pm 197.8$ & 0.126 \\
\hline HDL, mg/dl & $58.1 \pm 16.4$ & $53.2 \pm 13.7$ & $48.1 \pm 11.2$ & 0.005 \\
\hline $\mathrm{LDL}, \mathrm{md} / \mathrm{dl}$ & $102.5 \pm 25.6$ & $107.1 \pm 31.3$ & $125.3 \pm 31.6$ & 0.001 \\
\hline HbA1c, \% & $5.3 \pm 0.2$ & $6.0 \pm 0.6$ & $10.8 \pm 2.0$ & $<0.001$ \\
\hline FPG, mg/dl & $91.3 \pm 6.4$ & $111.1 \pm 19.0$ & $225.8 \pm 88.3$ & $<0.001$ \\
\hline PP30, mg/dl & $146.8 \pm 23.8$ & $195.0 \pm 32.1$ & $330.7 \pm 101.9$ & $9<0.001$ \\
\hline PP2, mg/dl & $103.0 \pm 17.7$ & $151.4 \pm 38.1$ & $397.6 \pm 117.1$ & $1<0.001$ \\
\hline Basal C-peptide, $\mathrm{ng} / \mathrm{m} / \S$ & $1.6 \pm 0.7$ & $1.9 \pm 0.8$ & $2.1 \pm 1.1$ & 0.037 \\
\hline Basal insulin, $\mu \mathrm{IU} / \mathrm{ml}$ & $10.6 \pm 3.3$ & $11.2 \pm 4.4$ & $12.3 \pm 6.5$ & 0.253 \\
\hline Insulin30, $\mu \mathrm{IU} / \mathrm{ml}$ & $56.9 \pm 25.2$ & $45.4 \pm 26.3$ & $17.4 \pm 9.5$ & $<0.001$ \\
\hline Insulin120, $\mu \mathrm{IU} / \mathrm{ml}$ & $38.0 \pm 25.5$ & $54.7 \pm 39.2$ & $23.7 \pm 17.6$ & $<0.001$ \\
\hline Insulinogenic index & $0.97 \pm 0.72$ & $0.39 \pm 0.47$ & $0.06 \pm 0.09$ & $<0.001$ \\
\hline HOMA-IR & $2.41 \pm 0.83$ & $3.05 \pm 1.27$ & $6.90 \pm 4.43$ & $<0.001$ \\
\hline Disposition index & $0.45 \pm 0.34$ & $0.14 \pm 0.20$ & $0.01 \pm 0.02$ & $<0.001$ \\
\hline HOMA- $\beta$ & $141.23 \pm 42.92$ & $93.27 \pm 40.79$ & $32.74 \pm 29.03$ & $3<0.001$ \\
\hline Glucose:insulin ratio & $9.39 \pm 3.04$ & $11.68 \pm 6.45$ & $22.62 \pm 14.49$ & $9<0.001$ \\
\hline WBC, count $/ \mathrm{mm}^{3}$ & $5.5 \pm 1.8$ & $6.0 \pm 1.6$ & $7.1 \pm 2.0$ & $<0.001$ \\
\hline hs-CRP & $0.370 \pm 1.560$ & $0.130 \pm 0.220$ & $0.730 \pm 2.020$ & 0.042 \\
\hline Neopterin, ng/m| & $0.545 \pm 0.253^{a}$ & $\mathrm{a} 0.577 \pm 0.274^{\mathrm{b}}$ & ${ }^{b} 0.672 \pm 0.268$ & $8 \quad 0.041$ \\
\hline
\end{tabular}

$\S$ Square root transformed.

a vs. $D M, p=0.048$.

${ }^{b}$ vs. $D M, p=0.028$.

NGT, normal glucose tolerance; T2D, type 2 diabetes; BMI, body mass index; SBP, systolic blood pressure; DBP, diastolic blood pressure; HDL, high density lipoprotein; $L D L$, low density lipoprotein; HbA1c, glycated hemoglobin; FPG, fasting plasma glucose, PP30, 30-min glucose concentration; PP2, 2-h glucose concentration; HOMA-IR, homeostatic model assessment-insulin resistance; HOMA- $\beta$, homeostatic model assessment $\beta$ cell; WBC, white blood cell; hs-CRP, high-sensitive C-reactive protein.

\section{Associations Between Serum Neopterin Concentration and Glucose Metabolic Status}

Serum neopterin correlated significantly with FPG $(r=0.251$, $p<0.001)$, with PP30 and PP2 of the 75-g OGTT $(r=0.259$ and 0.184 , respectively, both $p<0.05$ ), and with HbA1c level $(r=0.270, p<0.001)$ (Table 2). These correlations with serum glucose levels remained significant after adjusting for age and BMI. However, serum neopterin showed a significant correlation only with baseline insulin, not with 30-min or 120min insulin concentration of OGTT, which was not maintained after adjustment for age and BMI. For the glucose metabolismrelated parameters, serum neopterin correlated positively with HOMA-IR $(r=0.291, p<0.001)$ and inversely with the disposition index after adjusting for age and BMI $(r=-0.162$, $p<0.05)$. However, HOMA- $\beta$ and insulinogenic index were not significantly correlated with serum neopterin (data not shown). 
TABLE 2 | Partial correlations between serum neopterin concentration and glucose metabolism-related parameters.

\begin{tabular}{lcccc}
\hline & \multicolumn{2}{c}{ Unadjusted } & \multicolumn{2}{c}{ Adjusted for age and BMI } \\
\cline { 2 - 5 } & \multicolumn{1}{c}{$\boldsymbol{r}$} & $\boldsymbol{p}$ & $\boldsymbol{r}$ & $\boldsymbol{p}$ \\
\hline HbA1c, \% & 0.270 & $<0.001$ & 0.296 & 0.002 \\
FPG, mg/dl & 0.251 & 0.001 & 0.268 & 0.004 \\
PP30, mg/dl & 0.259 & $<0.001$ & 0.258 & 0.006 \\
PP2, mg/dl & 0.184 & 0.014 & 0.214 & 0.023 \\
Basal C-peptide, ng/ml & 0.251 & 0.001 & 0.242 & 0.010 \\
Basal insulin, $\mu$ IU/ml & 0.184 & 0.013 & 0.109 & 0.251 \\
HOMA-IR & 0.291 & $<0.001$ & 0.258 & 0.006 \\
Disposition index & -0.170 & 0.021 & -0.162 & 0.032 \\
\hline
\end{tabular}

The data were analyzed using Pearson correlational analysis. Neopterin concentration was square root transformed.

BMI, body mass index; FPG, fasting plasma glucose, PP30, 30-min glucose concentration; PP2, 2-h glucose concentration; HOMA-IR, homeostatic model assessment-insulin resistance.

\section{Relationship Between T2D Progression and Serum Neopterin Concentration}

Of the 184 participants, 108 were followed up for more than 6 months; the mean follow-up period was $56.94 \pm$ 32.83 months. During the follow-up, 39 patients progressed to T2D and 69 patients did not progress to T2D. Serum neopterin concentration did not differ significantly between those who progressed and those who did not progress to T2D (data not shown). The AUC value was 0.524 when the cstatistics were calculated using only neopterin concentration to predict the occurrence of T2D. However, model 3 (shown in Table 3), in which neopterin and C-peptide concentrations were considered together, gave an AUC value similar to that of HOMA-IR for predicting future T2D (AUC 0.649 and 0.624, respectively, $p=0.640$ ).

\section{DISCUSSION}

In the present study, we found that serum neopterin concentration was significantly associated with glucose metabolism-associated parameters, such as HOMA-IR, disposition index as well as serum glucose level and basal C-peptide. It was higher in patients with T2D than in those with NGT or prediabetes. In addition, considering both serum neopterin and C-peptide concentrations had a similar power to that of HOMA-IR in predicting the development of T2D.

A common feature of insulin resistance-related disorder, such as T2D is low-grade inflammation, which may be indirectly measured by the levels of neopterin or kynurenine metabolites (32-35). Inflammatory processes are involved in the progression of insulin resistance and $\beta$-cell dysfunction in individuals with prediabetes and contribute to the development of diabetes (36). It has been previously reported that serum neopterin level is associated with insulin resistance in a couple of population-based cohort studies $(37,38)$. The current report confirmed its association with insulin resistance (HOMA-IR) as well. Moreover, we found that serum neopterin level have a significant correlation with disposition index, a measure of acute insulin secretion of $\beta$-cell function. Neopterin or kynurenine metabolites were supposed to be related to $\beta$-cell function through the activation of apoptotic caspase, etc. (39-42). Considering the mechanisms responsible for the increased levels of neopterin or kynurenine metabolites, they are expected to increase in relation to $\mathrm{T} 2 \mathrm{D}$.

Increased kynurenine metabolites have been reported in the urine of rat and monkey models of diabetes (43). An elevation in the concentration of kynurenine pathway metabolites has been shown in human serum and urine samples of diabetic patients in comparison with that of non-diabetic controls $(43,44)$. On the contrary, neopterin was not higher in the diabetes group compared to the control group in a couple of populationbased cohorts $(45,46)$. These different outcomes in patients with diabetes may be due to uncontrolled factors that known to be potentially affect serum neopterin levels, such as age, BMI, hypoglycemic agents or diabetic complications. In this study, we evaluated the newly diagnosed patients with T2D who did not take any hypoglycemic agents and it can be considered the most reliable results to date by minimizing these effects.

Given the association of serum neopterin concentration, insulin resistance, and $\beta$-cell function, such as insulin secretion, we explored the serum neopterin concentration as a predictor of the progression to T2D. Among the 108 participants who were followed up for 6 months or more, there was no significant difference in serum neopterin concentration between progressors to future $\mathrm{T} 2 \mathrm{D}$ and non-progressors. In the C-statistics analysis for the occurrence of T2D with neopterin alone, the AUC was insignificantly as low as 0.524 [95\% confidence interval (CI), 0.423-0.623].

However, when both serum neopterin and C-peptide concentrations were considered together, the AUC value was 0.649 (95\% CI, 0.549-0.741), which was similar to that of the HOMA-IR (0.624, 95\% CI, 0.523-0.717) for predicting T2D. We can speculate that these results reflect the characteristics of Asian patients in the pathogenesis of diabetes. As is well-known, Asians have a higher risk of developing diabetes due to impaired insulin secretion which was induced by insufficient pancreatic $\beta$-cell mass or functional defects (31). Therefore, further studies are needed to clarify the mechanism of neopterin in the pathogenesis of the progression of diabetes in conjunction with the impaired beta cell function.

This study has some limitations. First, a prospective follow up study was conducted on limited number of study subjects. Only about half of the subjects were followed up for more than 6 months, and $35 \%$ of these subjects were progressed to T2D. Therefore, statistically significant result may not be obtained, especially in the comparative analysis of neopterin depending on the progression to T2D. 14 Second, the prediabetes group included people with impaired fasting glucose (IFG), impaired glucose tolerance (IGT), or both. IFG and IGT are different with respect to the degree of insulin resistance and insulin secretion (47), and it is possible that serum neopterin concentration may differ between IFG alone, IGT alone, and IFG+IGT together 
TABLE 3 | Comparison of AUCs for predicting the occurrence of type 2 diabetes.

\begin{tabular}{|c|c|c|c|c|c|c|c|}
\hline & AUC & SE & $95 \% \mathrm{Cl}$ & $\begin{array}{c}p \text {-value } \\
\text { (vs. model 1) }\end{array}$ & $\begin{array}{c}p \text {-value } \\
\text { (vs. model 2) }\end{array}$ & $\begin{array}{c}p \text {-value } \\
\text { (vs. model 3) }\end{array}$ & $\begin{array}{c}p \text {-value } \\
\text { (vs. model 4) }\end{array}$ \\
\hline Model 1 & 0.524 & 0.0601 & $0.423-0.623$ & & & & \\
\hline Model 2 & 0.609 & 0.0584 & $0.508-0.704$ & 0.391 & & & \\
\hline Model 3 & 0.649 & 0.0552 & $0.549-0.741$ & 0.105 & 0.244 & & \\
\hline Model 4 & 0.624 & 0.0572 & $0.523-0.717$ & 0.284 & 0.766 & 0.640 & \\
\hline Model 5 & 0.685 & 0.0528 & $0.586-0.773$ & 0.029 & 0.327 & 0.620 & 0.339 \\
\hline
\end{tabular}

Model 1, neopterin concentration; Model 2, basal C-peptide concentration; Model 3, basal C-peptide + neopterin concentrations; Model 4, HOMA-IR; Model 5, disposition index.

in large study subjects. Despite these limitations, our study had several strengths, the major one being that it is the first study to evaluate serum neopterin concentration according to glucose metabolism status with 75g OGTT (NGT, prediabetes, and T2D) in 184 participants. In addition, all patients diagnosed with T2D were drug-naïve, and blood samples were collected before the administration of medication. In 1989, Marchetti et al. reported a relationship between metformin level and plasma amino acid concentration, specifically that metformin might elevate plasma tryptophan level (48), which might affect the concentration of serum neopterin level even to a small extent. Therefore, it is important that we were able to exclude the effect of oral hypoglycemic agents by including only drug-naïve patients.

In conclusion, we found that serum neopterin concentration was closely related to glucose intolerance. As the predictor for future T2D, serum neopterin alone was not an independent factor, but it is significant when it considered with c-peptide level together. Further investigation of the relationship between serum neopterin concentration and glucose metabolism in a large study population would be helpful to understand the pathophysiology for the development of T2D.

\section{REFERENCES}

1. Shulman GI. Ectopic fat in insulin resistance, dyslipidemia, and cardiometabolic disease. $N$ Engl J Med. (2014) 371:1131-41. doi: 10.1056/NEJMra1011035

2. Robertson RP, Harmon J, Tran PO, Tanaka Y, Takahashi H. Glucose toxicity in beta-cells: type 2 diabetes, good radicals gone bad, and the glutathione connection. Diabetes. (2003). 52:581-7. doi: 10.2337/diabetes.52.3.581

3. Pickup JC, Crook MA. Is type II diabetes mellitus a disease of the innate immune system? Diabetologia. (1998) 41:1241-8. doi: 10.1007/s001250 051058

4. Pickup JC, Mattock MB, Chusney GD, Burt D. NIDDM as a disease of the innate immune system: association of acute-phase reactants and interleukin-6 with metabolic syndrome X. Diabetologia. (1997) 40:1286-92. doi: 10.1007/s001250050822

5. Duncan BB, Schmidt MI, Offenbacher S, Wu KK, Savage PJ, Heiss G. Factor VIII and other hemostasis variables are related to incident diabetes in adults. The Atherosclerosis Risk in Communities (ARIC) Study. Diabetes care. (1999) 22:767-72. doi: 10.2337/diacare.22.5.767

6. Festa A, D'Agostino R Jr., Tracy RP, Haffner SM. Elevated levels of acute-phase proteins and plasminogen activator inhibitor-1 predict the development of type 2 diabetes: the insulin resistance atherosclerosis study. Diabetes. (2002) 51:1131-7. doi: 10.2337/diabetes.51.4.1131

\section{AUTHOR CONTRIBUTIONS}

J-EL and SC designed the study. J-EL, TO, JM, KP, HJ, and SC contributed data interpretation. J-EL and SC collected and analyzed the data, and drafted the manuscript. All authors agreed on the final content of the manuscript.

\section{FUNDING}

This research was supported by grants from the Korea Health Technology R\&D Project through the Korea Health Industry Development Institute (KHIDI), funded by the Ministry of Health \& Welfare, Republic of Korea (HI11V-0005-020013) and the Medical Research Center (MRC) (NRF-2018R1A5A2024425) through the National Research Foundation of Korea (NRF) funded by the Ministry of Science, ICT and future Planning.

\section{ACKNOWLEDGMENTS}

The authors would like to thank Soo Lim (Seoul National University Bundang Hospital) for his contribution to the collection of blood samples and data interpretation.

7. Ford ES. Leukocyte count, erythrocyte sedimentation rate, and diabetes incidence in a national sample of US adults. Am J Epidemiol. (2002) 155:57-64. doi: 10.1093/aje/155.1.57

8. Freeman DJ, Norrie J, Caslake MJ, Gaw A, Ford I, Lowe GD, et al. Creactive protein is an independent predictor of risk for the development of diabetes in the West of Scotland Coronary Prevention Study. Diabetes. (2002) 51:1596-600. doi: 10.2337/diabetes.51.5.1596

9. Nakanishi N, Yoshida H, Matsuo Y, Suzuki K, Tatara K. White blood-cell count and the risk of impaired fasting glucose or Type II diabetes in middleaged Japanese men. Diabetologia. (2002) 45:42-8. doi: 10.1007/s001250200004

10. Feuerer M, Herrero L, Cipolletta D, Naaz A, Wong J, Nayer A, et al. Lean, but not obese, fat is enriched for a unique population of regulatory $\mathrm{T}$ cells that affect metabolic parameters. Nat Med. (2009) 15:930-9. doi: 10.1038/nm.2002

11. Nishimura S, Manabe I, Nagasaki M, Eto K, Yamashita H, Ohsugi $\mathrm{M}$, et al. $\mathrm{CD}^{+}$effector $\mathrm{T}$ cells contribute to macrophage recruitment and adipose tissue inflammation in obesity. Nat Med. (2009) 15:914-20. doi: $10.1038 / \mathrm{nm} .1964$

12. Rocha VZ, Folco EJ, Sukhova G, Shimizu K, Gotsman I, Vernon AH, et al. Interferon-gamma, a Th1 cytokine, regulates fat inflammation: a role for adaptive immunity in obesity. Circ Res. (2008) 103:467-76. doi: 10.1161/CIRCRESAHA.108.177105

13. Thewissen MM, Damoiseaux JG, Duijvestijn AM, van Greevenbroek MM, van der Kallen CJ, Feskens EJ, et al. Abdominal fat mass is associated with 
adaptive immune activation: the CODAM study. Obesity (Silver Spring). (2011) 19:1690-8. doi: 10.1038/oby.2010.337

14. Winer S, Chan Y, Paltser G, Truong D, Tsui H, Bahrami J, et al. Normalization of obesity-associated insulin resistance through immunotherapy. Nat Med. (2009) 15:921-9. doi: 10.1038/nm.2001

15. Nathan DM, Davidson MB, DeFronzo RA, Heine RJ, Henry RR, Pratley R, et al. Impaired fasting glucose and impaired glucose tolerance: implications for care. Diabetes Care. (2007) 30:753-9. doi: 10.2337/dc07-9920

16. Olefsky JM, Glass CK. Macrophages, inflammation, and insulin resistance. Аnnu Rev Physiol. (2010) 72:219-46. doi: 10.1146/annurevphysiol-021909-135846

17. Murr C, Widner B, Wirleitner B, Fuchs D. Neopterin as a marker for immune system activation. Curr Drug Metab. (2002) 3:175-87. doi: $10.2174 / 1389200024605082$

18. Connick JH, Stone TW. The role of kynurenines in diabetes mellitus. Med Hypotheses. (1985) 18:371-6. doi: 10.1016/0306-9877(85)90104-5

19. Alberati-Giani D, Ricciardi-Castagnoli P, Kohler C, Cesura AM. Regulation of the kynurenine metabolic pathway by interferon-gamma in murine cloned macrophages and microglial cells. J Neurochem. (1996) 66:996-1004. doi: 10.1046/j.1471-4159.1996.66030996.x

20. Meyramov G, Korchin V, Kocheryzkina N. Diabetogenic activity of xanturenic acid determined by its chelating properties? Transplant Proc. (1998) 30:2682-4.

21. Murakami E, Kotake Y. Studies on the xanthurenic acid-insulin complex. 3. Distribution of xanthurenic acid and formation of xanthurenic acid-insulin complex in serum. J. Biochem. (1972) 72:251-9.

22. Sucher R, Schroecksnadel K, Weiss G, Margreiter R, Fuchs D, Brandacher G. Neopterin, a prognostic marker in human malignancies. Cancer Lett. (2010) 287:13-22. doi: 10.1016/j.canlet.2009.05.008

23. Neurauter G, Schrocksnadel K, Scholl-Burgi S, Sperner-Unterweger B, Schubert C, Ledochowski M, et al. Chronic immune stimulation correlates with reduced phenylalanine turnover. Curr Drug Metab. (2008) 9:622-7. doi: $10.2174 / 138920008785821738$

24. American Diabetes, A. Erratum. Classification and diagnosis of diabetes. Sec. 2. In standards of medical care in diabetes-2016. Diabetes care 2016;39(Suppl. 1):S13-S22. Diabetes Care. (2016) 39:1653. doi: 10.2337/dc16-er09

25. Matthews DR, Hosker JP, Rudenski AS, Naylor BA, Treacher DF, Turner RC. Homeostasis model assessment: insulin resistance and beta-cell function from fasting plasma glucose and insulin concentrations in man. Diabetologia. (1985) 28:412-9.

26. Seltzer HS, Allen EW, Herron AL Jr., Brennan MT. Insulin secretion in response to glycemic stimulus: relation of delayed initial release to carbohydrate intolerance in mild diabetes mellitus. J Clin Invest. (1967) 46:323-35. doi: 10.1172/JCI105534

27. Abdul-Ghani MA, Tripathy D, DeFronzo RA. Contributions of beta-cell dysfunction and insulin resistance to the pathogenesis of impaired glucose tolerance and impaired fasting glucose. Diabetes Care. (2006) 29:1130-9. doi: $10.2337 /$ diacare. 2951130

28. Utzschneider KM, Prigeon RL, Faulenbach MV, Tong J, Carr DB, Boyko EJ, et al. Oral disposition index predicts the development of future diabetes above and beyond fasting and 2-h glucose levels. Diabetes Care. (2009) 32:335-41. doi: $10.2337 / \mathrm{dc} 08-1478$

29. Matsuda M, DeFronzo RA. Insulin sensitivity indices obtained from oral glucose tolerance testing: comparison with the euglycemic insulin clamp. Diabetes Care. (1999) 22:1462-70.

30. Legro RS, Finegood D, Dunaif A. A fasting glucose to insulin ratio is a useful measure of insulin sensitivity in women with polycystic ovary syndrome. $J$ Clin Endocrinol Metab. (1998) 83:2694-8. doi: 10.1210/jcem.83.8.5054

31. DeLong ER, DeLong DM, Clarke-Pearson DL. Comparing the areas under two or more correlated receiver operating characteristic curves: a nonparametric approach. Biometrics. (1988) 44:837-45. doi: 10.2307/2531595

32. Duncan BB, Schmidt MI, Pankow JS, Ballantyne CM, Couper D, Vigo A, et al. Low-grade systemic inflammation and the development of type 2 diabetes: the atherosclerosis risk in communities study. Diabetes. (2003) 52:1799-805. doi: 10.2337/diabetes.52.7.1799

33. Frick B, Schroecksnadel K, Neurauter G, Leblhuber F, Fuchs D. Increasing production of homocysteine and neopterin and degradation of tryptophan with older age. Clin Biochem. (2004) 37:684-7. doi: 10.1016/j.clinbiochem.2004.02.007
34. Midttun O, Ulvik A, Ringdal Pedersen E, Ebbing M, Bleie O, SchartumHansen $\mathrm{H}$, et al. Low plasma vitamin B-6 status affects metabolism through the kynurenine pathway in cardiovascular patients with systemic inflammation. $J$ Nutr. (2011) 141:611-7. doi: 10.3945/jn.110.133082

35. Wolowczuk I, Hennart B, Leloire A, Bessede A, Soichot M, Taront S, et al. Tryptophan metabolism activation by indoleamine 2,3-dioxygenase in adipose tissue of obese women: an attempt to maintain immune homeostasis and vascular tone. Am J Physiol Regul Integr Comp Physiol. (2012) 303:R13543. doi: 10.1152/ajpregu.00373.2011

36. Weber KS, Nowotny B, Strassburger K, Pacini G, Mussig K, Szendroedi J, et al. The role of markers of low-grade inflammation for the early time course of glycemic control, glucose disappearance rate, and beta-cell function in recently diagnosed type 1 and type 2 diabetes. Diabetes Care. (2015) 38:1758-67. doi: 10.2337/dc15-0169

37. Ledochowski M, Murr C, Widner B, Fuchs D. Association between insulin resistance, body mass and neopterin concentrations. Clin Chim Acta. (1999) 282:115-23.

38. Oxenkrug G, Tucker KL, Requintina P, Summergrad P. Neopterin, a marker of interferon-gamma-inducible inflammation, correlates with pyridoxal- $5^{\prime}$ phosphate, waist circumference, HDL-cholesterol, insulin resistance and mortality risk in adult boston community dwellers of Puerto Rican origin. Am J Neuroprot Neuroregen. (2011) 3:48-52. doi: 10.1166/ajnn.2011.1024

39. Kotake $\mathrm{Y}$, Ueda T, Mori T, Igaki S, Hattori M. Abnormal tryptophan metabolism and experimental diabetes by xanthurenic acid (XA). Acta Vitaminol Enzymol. (1975) 29:236-9.

40. Liu JJ, Raynal S, Bailbe D, Gausseres B, Carbonne C, Autier V, et al. Expression of the kynurenine pathway enzymes in the pancreatic islet cells. Activation by cytokines and glucolipotoxicity. Biochim Biophys Acta. (2015) 1852:980-91. doi: 10.1016/j.bbadis.2015.02.001

41. Malina HZ, Richter C, Mehl M, Hess OM. Pathological apoptosis by xanthurenic acid, a tryptophan metabolite: activation of cell caspases but not cytoskeleton breakdown. BMC Physiol. (2001) 1:7. doi: 10.1186/1472-6793-1-7

42. Okamoto H. Effect of quinaldic acid and its relatives on insulin-release from isolated Langerhans islets. Acta Vitaminol Enzymol. (1975) 29:227-31.

43. Hattori M, Kotake Y. Studies on the urinary excretion of xanthurenic acid in diabetics. Acta Vitaminol Enzymol. (1984) 6:221-8.

44. Munipally PK, Agraharm SG, Valavala VK, Gundae S, Turlapati NR. Evaluation of indoleamine 2,3-dioxygenase expression and kynurenine pathway metabolites levels in serum samples of diabetic retinopathy patients. Arch Physiol Biochem. (2011) 117:254-8. doi: 10.3109/13813455.2011.623705

45. Anwaar I, Gottsater A, Eriksson K, Jacobsson L, Lindgarde F, Mattiasson I. Increased plasma endothelin-1 and intraplatelet cyclic guanosine monophosphate in men with disturbed glucose metabolism. Diabetes Res Clin Pract. (2000) 50:127-36. doi: 10.1016/S0168-8227(00)00190-X

46. Vengen IT, Dale AC, Wiseth R, Midthjell K, Videm V. Neopterin predicts the risk for fatal ischemic heart disease in type 2 diabetes mellitus: longterm follow-up of the HUNT 1 study. Atherosclerosis. (2009) 207:239-44. doi: 10.1016/j.atherosclerosis.2009.04.003

47. Hanefeld M, Koehler C, Fuecker K, Henkel E, Schaper F, TemelkovaKurktschiev T. Insulin secretion and insulin sensitivity pattern is different in isolated impaired glucose tolerance and impaired fasting glucose: the -74 risk factor in impaired glucose tolerance for atherosclerosis and diabetes study. Diabetes Care. (2003) 26:868. doi: 10.2337/diacare.26.3.868

48. Marchetti P, Masiello P, Benzi L, Cecchetti P, Fierabracci V, Giannarelli R, et al. Effects of metformin therapy on plasma amino acid pattern in patients with maturity-onset diabetes. Drugs Exp Clin Res. (1989) 15:565-70.

Conflict of Interest Statement: The authors declare that the research was conducted in the absence of any commercial or financial relationships that could be construed as a potential conflict of interest.

Copyright () 2019 Lee, Oh, Moon, Park, Jang and Choi. This is an open-access article distributed under the terms of the Creative Commons Attribution License (CC BY). The use, distribution or reproduction in other forums is permitted, provided the original author(s) and the copyright owner(s) are credited and that the original publication in this journal is cited, in accordance with accepted academic practice. No use, distribution or reproduction is permitted which does not comply with these terms. 